\title{
Tsunamigenic Ratio of the Pacific Ocean earthquakes and a proposal for a Tsunami Index
}

\author{
A. Suppasri, F. Imamura, and S. Koshimura \\ Disaster Control Research Center, Graduate School of Engineering, Tohoku University, Japan \\ Correspondence to: A. Suppasri (anawat@tsunami2.civil.tohoku.ac.jp)
}

Received: 23 July 2011 - Revised: 6 January 2012 - Accepted: 6 January 2012 - Published: 17 January 2012

\begin{abstract}
The Pacific Ocean is the location where twothirds of tsunamis have occurred, resulting in a great number of casualties. Once information on an earthquake has been issued, it is important to understand if there is a tsunami generation risk in relation with a specific earthquake magnitude or focal depth. This study proposes a Tsunamigenic Ratio (TR) that is defined as the ratio between the number of earthquake-generated tsunamis and the total number of earthquakes. Earthquake and tsunami data used in this study were selected from a database containing tsunamigenic earthquakes from prior 1900 to 2011 . The TR is calculated from earthquake events with a magnitude greater than 5.0, a focal depth shallower than $200 \mathrm{~km}$ and a sea depth less than $7 \mathrm{~km}$. The results suggest that a great earthquake magnitude and a shallow focal depth have a high potential to generate tsunamis with a large tsunami height. The average TR in the Pacific Ocean is 0.4, whereas the TR for specific regions of the Pacific Ocean varies from 0.3 to 0.7 . The TR calculated for each region shows the relationship between three influential parameters: earthquake magnitude, focal depth and sea depth. The three parameters were combined and proposed as a dimensionless parameter called the Tsunami Index (TI). TI can express better relationship with the TR and with maximum tsunami height, while the three parameters mentioned above cannot. The results show that recent submarine earthquakes had a higher potential to generate a tsunami with a larger tsunami height than during the last century. A tsunami is definitely generated if the TI is larger than 7.0. The proposed TR and TI will help ascertain the tsunami generation risk of each earthquake event based on a statistical analysis of the historical data and could be an important decision support tool during the early tsunami warning stage.
\end{abstract}

\section{Introduction}

Just after an earthquake occurs, primary earthquake information can be accessed via specialized websites, such as the homepage of the US Geological Survey (USGS 2011), and more related scientific information can be obtained from the Global Centroid Moment Tensor (Global CMT, 2011). The condition of launching tsunami warning bulletins is dependent upon a pre-calculated tsunami database in the warning systems. The Japan Meteorological Agency introduced a computer-aided simulation system in 1999 for quantitative tsunami forecasting, in which tsunami arrival times and heights are computed and stored in a database for the forecasting of tsunamis after an earthquake actually occurs (Imamura and Abe, 2009). However, the system is still not able to clearly determine whether an earthquake will generate a tsunami or not. Necessary earthquake data for considering the occurrence of a tsunami are available, including the earthquake magnitude and focal depth. Similar to earthquakes, the first attempt to establish a tsunami magnitude was conducted by Iida et al. (1967). From data of tsunamis in the Pacific Ocean, the tsunami magnitude was calculated by taking the logarithm to base 2 of a physical measurement of the tsunami, such as the maximum wave height observed at the coast or measured at the tide gauges. Abe (1979) also developed a magnitude scale defined by the logarithm of the maximum amplitude of far-field tsunami waves measured by tide gauges. These two tsunami magnitudes are widely used to express a physical property of a tsunami. The application of the tsunami magnitude has been used for the tsunamis occurring in the seas surrounding Italy (Tinti, 1991) and the Central American tsunamis (Hatori, 1995). From the point of view of the focal depth, Satake and Tanioka (1999) classified tsunamigenic earthquakes in subduction zones into three types: earthquakes at the plate interface (typical interplate 
Table 1. Global tsunamis causing 3000 or more deaths. (NGDC tsunami database: http://www.ngdc.noaa.gov/hazard/tsu.shtml).

\begin{tabular}{rlrrr}
\hline Year & $\begin{array}{l}\text { Earthquake } \\
\text { location }\end{array}$ & $\begin{array}{r}\text { Magnitude } \\
M\end{array}$ & $\begin{array}{r}\text { Focal depth } \\
(\mathrm{km})\end{array}$ & $\begin{array}{r}\text { Estimated death } \\
\text { or missing }\end{array}$ \\
\hline 365 & Crete, Greece & 8.0 & & 5700 \\
1498 & Enshunada Sea, Japan & 8.6 & 1 & 31000 \\
1586 & Ise Bay, Japan & 8.2 & & 8000 \\
1605 & Nankaido, Japan & 7.9 & & 5000 \\
1611 & Sanriku, Japan & 8.1 & & 5000 \\
1687 & Southern Peru & 8.5 & 30 & $* 5000$ \\
1703 & Boso Peninsula, Japan & 8.2 & 1 & $* 5233$ \\
1707 & Nankaido, Japan & 8.4 & 1 & 30000 \\
1746 & Central Peru & 8.0 & 30 & 4800 \\
1755 & Lisbon, Portugal & 8.5 & & 60000 \\
1771 & Ryukyu Islands, Japan & 7.4 & 1 & 13486 \\
1854 & Nankaido, Japan & 8.4 & & 3000 \\
1896 & Sanriku, Japan & 8.5 & 1 & $* 27122$ \\
1933 & Sanriku, Japan & 8.4 & 25 & 3000 \\
1941 & Andaman Sea, India & 7.6 & 55 & 5000 \\
1945 & Makran, Pakistan & 8.0 & & 4000 \\
1952 & Kamchatka, Russia & 8.5 & 45 & 4000 \\
1976 & Moro Gulf, Philippines & 8.1 & 33 & 4456 \\
2004 & Banda Aceh, Indonesia & 9.2 & 30 & $* 227898$ \\
2011 & East Japan & 9.0 & 24 & $* 19296$ \\
\hline
\end{tabular}

* May include earthquake casualties.

events), earthquakes in the outer rise within the subducting slab or overlying crust (intraplate events), and "tsunami earthquakes" that generate considerably larger tsunamis than expected from the seismic waves. The depth range of interplate earthquake sources is $10-40 \mathrm{~km}$, whereas the source region of tsunami earthquakes is at a shallower extension near the trench axis. Thus, large magnitude earthquakes that occur at a shallow depth might have the potential to generate a tsunami.

In general, the displacement and fault size of an earthquake can be estimated by an empirical relation based on historical tsunami magnitude data, such as Wells and Coppersmith (1994), Okada and Tanioka (1998) and Papazachos et al. (2004). After the primary earthquake information is obtained, namely location, magnitude and focal solution (including focal depth and strike, dip and rake angle), other fault parameters, such as displacement and fault size, can also be estimated. These parameters are used as input in tsunami generation models to calculate the vertical seafloor displacement, which later becomes a tsunami initial level. The calculation is based on the two extensively used theories of Mansinha and Smylie (1971) and Okada (1985). The Asian Disaster Preparedness Center (ADPC) (2009) ascertained that the maximum and minimum displacements are equal for results calculated from both theories and that only minor differences could be observed in the overall shape of the computed deformation fields. Moreover, the effect of focal depth, dip and rake angles on the ocean bottom deformation was shown by Ruangrassamee (2006) who calculated deformation for focal depth varying from 10 to $100 \mathrm{~km}$ by applying the Mansinha and Smylie theory. The results show remarkably different effects on the vertical seafloor displacement. Therefore, it is supported that earthquake magnitude and focal depth play an important role in the generation of a tsunami. In addition, the sea depth at the location where an earthquake occurs also plays an important role for tsunami generation. This is because a large seafloor displacement in a deep sea induces the displacement of a large amount of sea water that later has a higher potential to generate a tsunami. This study proposes a new term, the "Tsunamigenic Ratio" (TR) that is defined as the ratio between the number of earthquake-generated tsunamis and the total number of earthquakes. The Tsunamigenic Ratio will help ascertain the tsunami generation risk of each earthquake event based on a statistical analysis of the historical data if the earthquake magnitude, focal depth and sea depth are known.

\section{Tsunamis in the Pacific Ocean}

The National Geophysical Data Center (NGDC) tsunami database at the National Oceanic and Atmospheric Administration (NOAA) provides 2400 events (NOAA, 2011c). The global distribution of these tsunami sources is $63 \%$ in the Pacific Ocean, $21 \%$ in the Mediterranean Sea, $5 \%$ in the Atlantic Ocean, $4 \%$ in the Caribbean Sea, $6 \%$ in the Indian 
Table 2. Tsunamis causing deaths from greater than $1000 \mathrm{~km}$ from the source location. (NGDC tsunami database: http://www.ngdc.noaa. gov/hazard/tsu.shtml).

\begin{tabular}{|c|c|c|c|c|c|c|}
\hline \multirow[t]{2}{*}{ Year } & \multirow{2}{*}{$\begin{array}{l}\text { Earthquake } \\
\text { location }\end{array}$} & \multirow{2}{*}{$\begin{array}{r}\text { Magnitude } \\
M\end{array}$} & \multirow{2}{*}{$\begin{array}{r}\text { Focal depth } \\
(\mathrm{km})\end{array}$} & \multicolumn{2}{|c|}{$\begin{array}{l}\text { Estimated death } \\
\text { or missing }\end{array}$} & \multirow{2}{*}{$\begin{array}{l}\text { Distant locations } \\
\text { that reported casualties }\end{array}$} \\
\hline & & & & Local & Distant & \\
\hline 1837 & Southern Chile & 8.5 & & 0 & 16 & USA (Hawaii) \\
\hline 1868 & Northern Chile & 8.5 & 25 & $* 25000$ & 1 & New Zealand, Southern Chile \\
\hline 1877 & Northern Chile & 8.3 & 40 & Hundreds & Thousands & Fiji, Japan, Peru, USA (Hawaii) \\
\hline 1923 & Kamchatka, Russia & 8.3 & 19 & 2 & 1 & USA (Hawaii) \\
\hline 1946 & Alaska, USA & 8.1 & 50 & 5 & 160 & USA (California, Hawaii) \\
\hline 1960 & Central Chile & 9.5 & 33 & 1000 & 283 & Japan, Philippines, USA (California, Hawaii) \\
\hline 1964 & Alaska, USA & 9.2 & 23 & 106 & 18 & USA (California, Oregon) \\
\hline 2004 & Banda Aceh, Indonesia & 9.3 & 30 & $* 175827$ & 52071 & $\begin{array}{l}\text { Bangladesh, India, Kenya, Maldives, Myanmar, } \\
\text { Seychelles, Somalia, South Africa, Sri Lanka, } \\
\text { Tanzania, Thailand, Yemen }\end{array}$ \\
\hline 2011 & East Japan & 9.0 & 24 & 19294 & 2 & Indonesia and USA (California) \\
\hline
\end{tabular}

* May include earthquake casualties.

Ocean and $1 \%$ in the Black Sea. Most of these tsunamis were generated by earthquakes $(83 \%)$ or earthquakes that caused landslides $(6 \%)$. The remaining events were caused by landslides (2\%), volcanic eruptions (6\%), and unknown sources $(3 \%)$. If the casualty number of 3000 is selected to classify an event as a deadly tsunami, there are 16 of such events in the Pacific region out of the total of 20 events, as shown in Table 1. The earthquake that induced deadly tsunamis did not necessary have large magnitudes only, but also occurred at shallow regions less than $50 \mathrm{~km}$. In Japan, where the number of casualties is the highest, the focal depth of some earthquakes is as shallow as less than $10 \mathrm{~km}$ (Sato, 1995). Damage to people's lives in the past was not only caused by local tsunamis but also by distant tsunamis, with transoceanic tsunami causing deaths greater than $1000 \mathrm{~km}$ far from the source over the Pacific Ocean, as shown in Table 2. In the Pacific Ocean, one can find eight events out of nine global events. In some events, the distant tsunami caused a higher number of casualties in the remote area than in the local area. Most of the distant tsunamis originated from earthquakes with a magnitude greater than 8.3 that occurred at the eastern Pacific side, such as in Chile and in the US, and caused damage to the western side, such as in Japan, the Philippines and New Zealand. Though Japan suffered a great loss of lives from local tsunamis generated by earthquakes with magnitude smaller than 8.5 before the 2011 event, earthquakes at the shallow region generated higher vertical ocean bottom deformation and resulted in a powerful tsunami (Satake and Tanioka 1999), such as the 1986 Sanriku and the 1946 Alaska cases (Kanamori 1972). In contrast, gigantic earthquakes with a magnitude 9.0 or greater in Chile, Alaska, Indonesia and Japan had damage potential across the Pacific Ocean.
Moreover, most tsunamigenic earthquakes occur along subduction zones or trenches where the sea depth is as deep as many thousands meters.

According to the problem and information stated above, the characteristics for the next tsunami are still unclear. This study will quantify the characteristics of earthquakegenerated tsunamis using the historical events in the Pacific Ocean. The proposed Tsunamigenic Ratio (TR) is defined as the ratio between the number of earthquake-generated tsunamis and the total number of earthquakes (Suppasri et al., $2011 \mathrm{a}, \mathrm{b}$ ). This idea is the same as that proposed by Okada and Tanioka (1998), but their study was limited to Japan and did not provide much detailed information. Gusiakov (2005) proposed the Tsunami Efficiency (TE) in the Pacific Ocean as the ratio between the number of tsunamis, including those generated by landslides and of unknown origins, and the total number of the coastal and submarine earthquakes. However, the TE value may exceed 1 , and it does not reflect the characteristics most likely to occur as the earthquake-generated tsunami. By considering the earthquake magnitude, focal depth and sea depth as the primary parameters in the generation of a tsunami, this study can provide more information on the tsunami generation ratio if future earthquake-related parameters are known.

\section{Earthquake data and processing method}

Earthquake-generated tsunamis and earthquake events can be accessed by the NGDC global significant earthquake database website (NOAA, 2011b). On the data selection page, we can select whether the earthquake event was associated with tsunami or not. Therefore, the historical earthquake 
events are divided into two groups: tsunami-associated events and tsunami-non-associated events. Tsunami related information for the tsunami-associated events can be accessed by the Global Historical Tsunami Database website (NOAA, 2011c). Consequently, the TR value is calculated for each specific range of earthquake magnitude, focal depth and sea depth. However, the earthquake magnitude is not compatible with the earthquake magnitude scale because the primary earthquake magnitude can be measured using several different scales. The primary magnitude is chosen from the available magnitude scale in this order: the moment magnitude $\left(M_{\mathrm{w}}\right)$, the surface wave magnitude $\left(M_{\mathrm{S}}\right)$ and the body wave magnitude $\left(M_{\mathrm{b}}\right)$. Nevertheless, Scordilis (2006) derived relationships between $M_{\mathrm{S}}$ and $M_{\mathrm{w}}$ and between $M_{\mathrm{b}}$ with $M_{\mathrm{w}}$. The $M_{\mathrm{s}}-M_{\mathrm{w}}$ relation has a bilinear changing slope at $M_{\mathrm{w}}=6.2$, while the $M_{\mathrm{b}}-M_{\mathrm{w}}$ relation can be plotted until 6.2. That means that the earthquake magnitude, $M$, can also be defined as either $M_{\mathrm{w}}$ or $M_{\mathrm{s}}$. Based on the tsunami data in Japan, Okada and Tanioka (1998) mentioned that an earthquake with focal depth deeper than $90 \mathrm{~km}$ could not generate a tsunami. Moreover, most tsunamis were generated when the Japanese earthquake magnitude, $M_{\mathrm{j}}$, was greater than $7.0\left(M_{\mathrm{w}}=6.9\right)$ and occurred at a very low ratio if $M_{\mathrm{j}}$ was smaller than $6.2\left(M_{\mathrm{w}}=6.3\right)$. Gusiakov (2005) used 1201 events of the coastal and submarine earthquakes with magnitude $M_{\mathrm{s}} \geq 7.0$ and focal depth $\leq 100 \mathrm{~km}$ that occurred in the Pacific Ocean during the last 100 years (from 1901 to 2000). In addition, the term "coastal" means that they also took into account the earthquakes located within $100 \mathrm{~km}$ inland for the events with $7.0 \leq M_{\mathrm{S}} \leq 8.0$ and $200 \mathrm{~km}$ in-land for the events with $M_{\mathrm{S}}>8.0$.

The Pacific Ocean is geographically divided into 9 regions: New Zealand-Tonga (NZT), New Guinea-Solomon (NGS), Indonesia (IND), the Philippines (PHI), Japan (JAP), KurilKamchatka (K-K), Alaska-Aleutians (A-A), Central America (CAM) and South America (SAM), following the zoning used in the NGDC map (Lockridge and Smith, 1984; Gusiakov, 2005). Table 3 summarizes the information on the boundaries for each region, and the map is illustrated in Fig. 1. This study considers the NGDC database, which contains earthquake events from $200 \mathrm{BC}$ to 2011 (more precisely from year -193 to 2011). Regarding the level of completeness of earthquake and tsunami catalogs and the accuracy of parameters that greatly vary over time, four different time periods can be distinguished: pre-instrumental (prior 1900), early instrumental (1900-1962), instrumental (1963-1990) and modern instrumental (1991 to 2011). The earthquake events exclude an event when the epicenter was located farther than $50 \mathrm{~km}$ from a shoreline. In some cases, fault width of megathrust earthquakes in subduction zones can be as large, for instance, as $150 \mathrm{~km}$ for $M=9.3$ of the 2004 Sumatra Earthquake (Suppasri et al., 2011c) and $200 \mathrm{~km}$ for $M=$ 9.0 of the 2011 Great East Japan Earthquake (Suppasri et al., 2012c). However, maximum width of continental faults for $M<7.5$ earthquake estimated using a formula proposed by

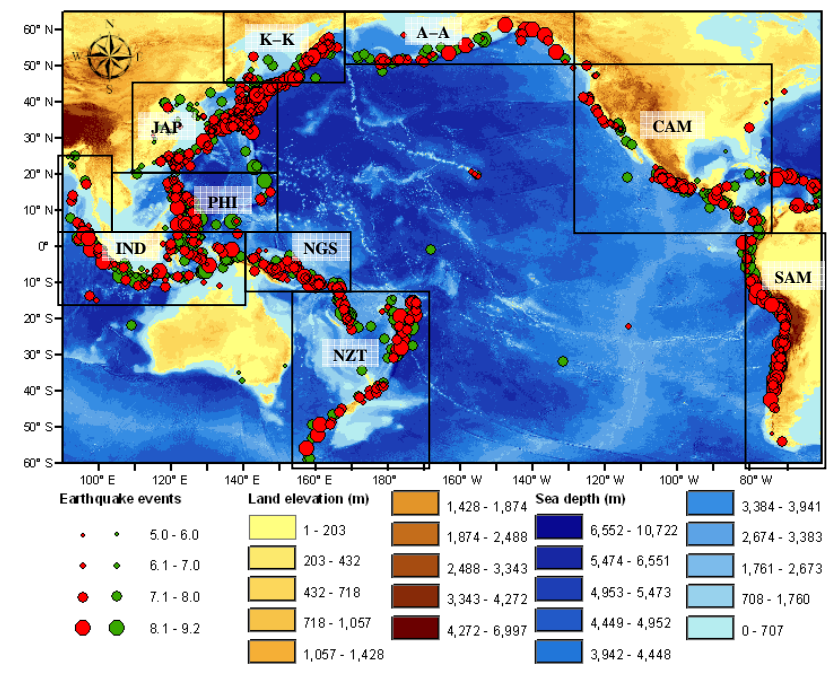

Fig. 1. Earthquake events in the Pacific Ocean (red: with tsunami events and green: without tsunami event).

Papazachos et al. (2004) is about $25 \mathrm{~km}$ and about $100 \mathrm{~km}$ for $M<8.5$ earthquake in subduction zones. Therefore, sea depth for these in-land earthquakes is reasonably assumed to be obtained by taking a sea depth value at a point where the distance is within $50 \mathrm{~km}$ perpendicularly far from the epicenter. The method of extracting coastal earthquakes was adapted from the tsunami casualty estimation method developed by Suppasri et al. (2012a, b). They applied the concept of image processing and the Laplacian mask over the global bathymetry data of Pacific region. Shorelines of every 2-min grid from ETOPO2 (NOAA 2011a) can be found by the mentioned method. The coastal zone is then expanded until it reaches $50 \mathrm{~km}$. For tsunami event selection from the NGDC database, the code " $1=$ Earthquake" was used from the total of 12 codes describing the tsunami cause, and the codes " $4=$ definite tsunami" and " $3=$ probable tsunami" were used from the total of six codes describing the tsunami event validity. Consequently, the TR is calculated from an earthquake event with a magnitude ranging from 5.0 to 9.0 , focal depth up to $200 \mathrm{~km}$ and sea depth down to a depth of $7000 \mathrm{~m}$.

\section{Tsunamigenic Ratio of the Pacific Ocean earthquakes}

The total numbers of tsunami events for the four different time periods mentioned above are 466, 499, 337 and 381, respectively, as summarized in Table 4a. The average TR in the Pacific Ocean for each region in each time period can be calculated using the total number of tsunami-associated event (a), of tsunami-non-associated event (b), and of event (c) (Table 4a). TR was calculated by dividing "a" by "c" with resulting TR value of $0.46,0.41,0.47$ and 0.40 for the four periods, respectively. It can be seen from Table 4a that 
Table 3. Tsunamigenic regions along the Pacific Ring of Fire.

\begin{tabular}{llrr}
\hline Regions & Abbreviations & Lower-Left point & Upper-Right point \\
\hline New Zealand-Tonga & NZT & $60^{\circ} \mathrm{S} 155^{\circ} \mathrm{E}$ & $12^{\circ} \mathrm{S} 168^{\circ} \mathrm{W}$ \\
New Guinea-Solomon & NGS & $12^{\circ} \mathrm{S} 141^{\circ} \mathrm{E}$ & $5^{\circ} \mathrm{N} 170^{\circ} \mathrm{E}$ \\
Indonesia & $15^{\circ} \mathrm{S} 90^{\circ} \mathrm{E}$ & $5^{\circ} \mathrm{N} 141^{\circ} \mathrm{E}$ \\
& IND1 & $5^{\circ} \mathrm{N} 90^{\circ} \mathrm{E}$ & $25^{\circ} \mathrm{N} 105^{\circ} \mathrm{E}$ \\
Philippines & IND2 & $5^{\circ} \mathrm{N} 105^{\circ} \mathrm{E}$ & $20^{\circ} \mathrm{N} 150^{\circ} \mathrm{E}$ \\
Japan & JAP & $20^{\circ} \mathrm{N} 110^{\circ} \mathrm{E}$ & $45^{\circ} \mathrm{N} 150^{\circ} \mathrm{E}$ \\
Kuril-Kamchatka & K-K & $45^{\circ} \mathrm{N} 135^{\circ} \mathrm{E}$ & $65^{\circ} \mathrm{N} 170^{\circ} \mathrm{E}$ \\
Alaska-Aleutians & A-A & $50^{\circ} \mathrm{N} 170^{\circ} \mathrm{E}$ & $65^{\circ} \mathrm{N} 128^{\circ} \mathrm{W}$ \\
Central America & CAM & $5.5^{\circ} \mathrm{N} 128^{\circ} \mathrm{W}$ & $50^{\circ} \mathrm{N} 75^{\circ} \mathrm{W}$ \\
South America & SAM & $60^{\circ} \mathrm{S} 82^{\circ} \mathrm{W}$ & $5.5^{\circ} \mathrm{N} 65^{\circ} \mathrm{W}$ \\
\hline
\end{tabular}

Table 4a. Average tsunamigenic ratio TR along the Pacific Ring of Fire by separating data into four periods.

\begin{tabular}{|c|c|c|c|c|c|c|c|c|c|c|c|c|c|c|c|c|}
\hline \multirow{2}{*}{ Reg. } & \multicolumn{4}{|c|}{ Prior 1900} & \multicolumn{4}{|c|}{ 1900-1962 } & \multicolumn{4}{|c|}{ 1963-1990 } & \multicolumn{4}{|c|}{ 1991-2011 } \\
\hline & $\mathrm{a}$ & $\mathrm{b}$ & $\mathrm{c}$ & TR & $\mathrm{a}$ & $\mathrm{b}$ & $\mathrm{c}$ & TR & $\mathrm{a}$ & $\mathrm{b}$ & $\mathrm{c}$ & $\mathrm{TR}$ & $\mathrm{a}$ & $\mathrm{b}$ & $\mathrm{c}$ & TR \\
\hline NZT & 5 & 0 & 5 & 1.00 & 15 & 35 & 50 & 0.30 & 15 & 13 & 28 & 0.54 & 24 & 9 & 33 & 0.73 \\
\hline NGS & 4 & 0 & 4 & 1.00 & 25 & 17 & 42 & 0.60 & 21 & 15 & 36 & 0.58 & 11 & 6 & 17 & 0.65 \\
\hline IND & 41 & 14 & 55 & 0.75 & 18 & 39 & 57 & 0.32 & 10 & 40 & 50 & 0.20 & 30 & 76 & 106 & 0.28 \\
\hline PHI & 6 & 58 & 64 & 0.09 & 17 & 30 & 47 & 0.36 & 9 & 15 & 24 & 0.38 & 8 & 18 & 26 & 0.31 \\
\hline JAP & 104 & 79 & 183 & 0.57 & 74 & 68 & 142 & 0.52 & 59 & 31 & 90 & 0.66 & 43 & 41 & 84 & 0.51 \\
\hline $\mathrm{K}-\mathrm{K}$ & 4 & 5 & 9 & 0.44 & 11 & 19 & 30 & 0.37 & 11 & 1 & 12 & 0.92 & 9 & 3 & 12 & 0.75 \\
\hline $\mathrm{A}-\mathrm{A}$ & 5 & 2 & 7 & 0.71 & 5 & 14 & 19 & 0.26 & 10 & 3 & 13 & 0.77 & 7 & 0 & 7 & 1.00 \\
\hline CAM & 14 & 59 & 73 & 0.19 & 21 & 58 & 79 & 0.27 & 9 & 43 & 52 & 0.17 & 11 & 56 & 67 & 0.16 \\
\hline SAM & 30 & 36 & 66 & 0.45 & 18 & 15 & 33 & 0.55 & 14 & 18 & 32 & 0.44 & 10 & 19 & 29 & 0.34 \\
\hline Total & 213 & 253 & 466 & 0.46 & 204 & 295 & 499 & 0.41 & 158 & 179 & 337 & 0.47 & 153 & 228 & 381 & 0.40 \\
\hline
\end{tabular}

Note: $\mathrm{a}=$ tsunami-associated events, $\mathrm{b}=$ tsunami-non-associated events and $\mathrm{c}=$ total number of events.

TR prior to 1900 (pre-instrumental) fluctuates quite a bit: from 0.09 in PHI to 1.00 in NZT and NGS. K-K and AA have high TR of more than 0.75 for both $1963-1900$ and 1991-2011. CAM has the lowest TR of about 0.20 for the whole time period. Table $4 \mathrm{~b}$ summarizes number of events and TR for accumulated data for the total period and also for periods 1990-2011, 1963-2011 and 1991-2011. TR in Table $4 \mathrm{~b}$ is approximately 0.40 for all time spans, meaning that value of TR is consistent with time, while different by region. In general, JAP provides the largest number of the tsunamiassociated (a) events (280 out of 728 events) and of total (c) events (499 out of 1683 events), which is about one-third of the total data. If the time span is considered until the pre and early instrumental periods, NZT, NGS, JAP, K-K and A-A are regions where TR is about $0.5-0.6$. On the other hand, if only the instrumental and modern instrumental periods are considered, TR for those regions is increased as high as 0.60.8. TR for IND and PHI is approximately the same of about 0.3 , while TR for CAM and SAM is 0.2 and 0.4 , respectively.
Tsunamigenic ratios for each region are then plotted against the three parameters that have related potential to generate a tsunami (Fig. 2): earthquake magnitude (Fig. 2a), focal depth (Fig. 2b) and sea depth (Fig. 2c). From Fig. 2a, greater earthquake magnitude has a greater potential to generate a tsunami because the TR at $M=6.0$ is approximately 0.20 and increases to 0.50 at $M=7.5$ and to more than 0.80 at $M=8.5$. Influence from the focal depth is shown in Fig. 2b. Shallower focal depth has high potential for tsunami generation. A TR of 0.80 can be found when the focal depth is less than $30 \mathrm{~km}$ and gradually reduces to below 0.20 when the depth is deeper than $100 \mathrm{~km}$. Sea depth at a point of each earthquake epicenter, which is considered as a representative value of the whole rupture area for quick information after an earthquake occurrence, is obtained from the global bathymetry data (ETOPO2), and the plot is shown in Fig. 2c. In general, TR increases when sea depth is increased, and the TR increases rapidly when the sea depth is as deep as $1000 \mathrm{~m}$, and varies from 0.40 to 0.70 when the sea depth is deeper than $1000 \mathrm{~m}$. This large variation can be seen in all 
Table 4b. Average tsunamigenic ratio TR along the Pacific Ring of Fire by separating data into four periods.

\begin{tabular}{|c|c|c|c|c|c|c|c|c|c|c|c|c|c|c|c|c|}
\hline \multirow{2}{*}{ Reg. } & \multicolumn{4}{|c|}{ Prior 1900-2011 } & \multicolumn{4}{|c|}{ 1900-2011 } & \multicolumn{4}{|c|}{ 1963-2011 } & \multicolumn{4}{|c|}{$1991-2011$} \\
\hline & $\mathrm{a}$ & $\mathrm{b}$ & $\mathrm{c}$ & TR & $\mathrm{a}$ & $\mathrm{b}$ & $\mathrm{c}$ & TR & $\mathrm{a}$ & $\mathrm{b}$ & $\mathrm{c}$ & TR & $\mathrm{a}$ & $\mathrm{b}$ & $\mathrm{c}$ & TR \\
\hline NZT & 59 & 57 & 116 & 0.51 & 54 & 57 & 111 & 0.49 & 39 & 22 & 61 & 0.64 & 24 & 9 & 33 & 0.73 \\
\hline NGS & 61 & 38 & 99 & 0.62 & 57 & 38 & 95 & 0.60 & 32 & 21 & 53 & 0.60 & 11 & 6 & 17 & 0.65 \\
\hline IND & 99 & 169 & 268 & 0.37 & 58 & 155 & 213 & 0.27 & 40 & 116 & 156 & 0.26 & 30 & 76 & 106 & 0.28 \\
\hline PHI & 40 & 121 & 161 & 0.25 & 34 & 63 & 97 & 0.35 & 17 & 33 & 50 & 0.34 & 8 & 18 & 26 & 0.31 \\
\hline JAP & 280 & 219 & 499 & 0.56 & 176 & 140 & 316 & 0.56 & 102 & 72 & 174 & 0.59 & 43 & 41 & 84 & 0.51 \\
\hline $\mathrm{K}-\mathrm{K}$ & 35 & 28 & 63 & 0.56 & 31 & 23 & 54 & 0.57 & 20 & 4 & 24 & 0.83 & 9 & 3 & 12 & 0.75 \\
\hline $\mathrm{A}-\mathrm{A}$ & 27 & 19 & 46 & 0.59 & 22 & 17 & 39 & 0.56 & 17 & 3 & 20 & 0.85 & 7 & 0 & 7 & 1.00 \\
\hline CAM & 55 & 216 & 271 & 0.20 & 41 & 157 & 198 & 0.21 & 20 & 99 & 119 & 0.17 & 11 & 56 & 67 & 0.16 \\
\hline SAM & 72 & 88 & 160 & 0.45 & 42 & 52 & 94 & 0.45 & 24 & 37 & 61 & 0.39 & 10 & 19 & 29 & 0.34 \\
\hline Total & 728 & 955 & 1683 & 0.43 & 515 & 702 & 1217 & 0.42 & 311 & 407 & 718 & 0.43 & 153 & 228 & 381 & 0.40 \\
\hline
\end{tabular}

Note: $\mathrm{a}=$ tsunami-associated events, $\mathrm{b}=$ tsunami-non-associated events and $\mathrm{c}=$ total number of events.
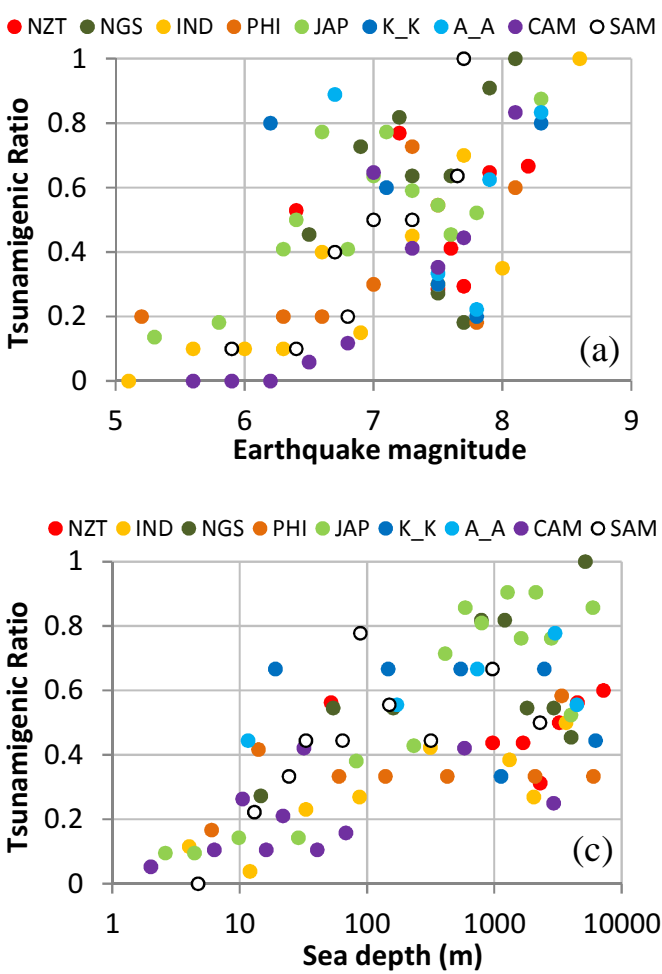

Fig. 2. Tsunamigenic ratio for each region.

figures shown. For the entire Pacific Ocean, the plots were made using all data and were separated into three different time periods, 1900-2011 (green line), 1960-2011 (blue line) and 1991-2011 (red line), respectively, as shown in Fig. 3c, with different affecting parameters, earthquake magnitude (Fig. 3a), focal depth (Fig. 3b) and sea depth (Fig. 3c). Power function was applied for regression analysis to fit the data because it provides higher $R^{2}$ in all cases. A comparison of data accuracy and correlation can be made among three different
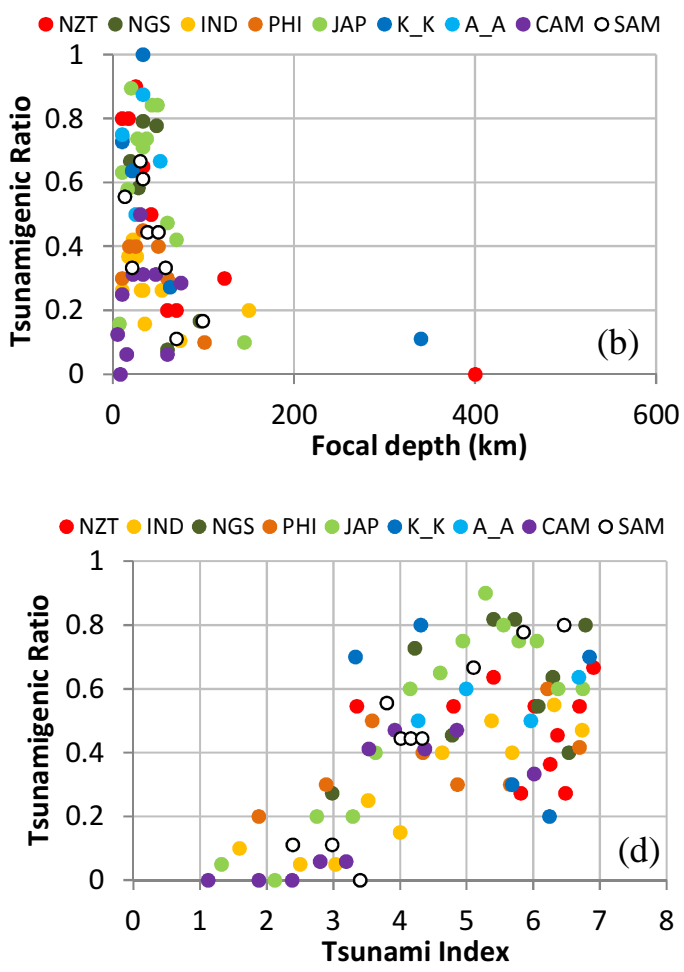

time periods using the $R^{2}$ values. It can be seen from the regression analysis that values of $R^{2}$ in all cases have improved when more precise data (during 1960-2011 or 1991-2011) are used. The curves obtained from the regression analysis can be used for the future estimation of TR for each different time span when earthquake magnitude, focal depth and sea depth are known. 

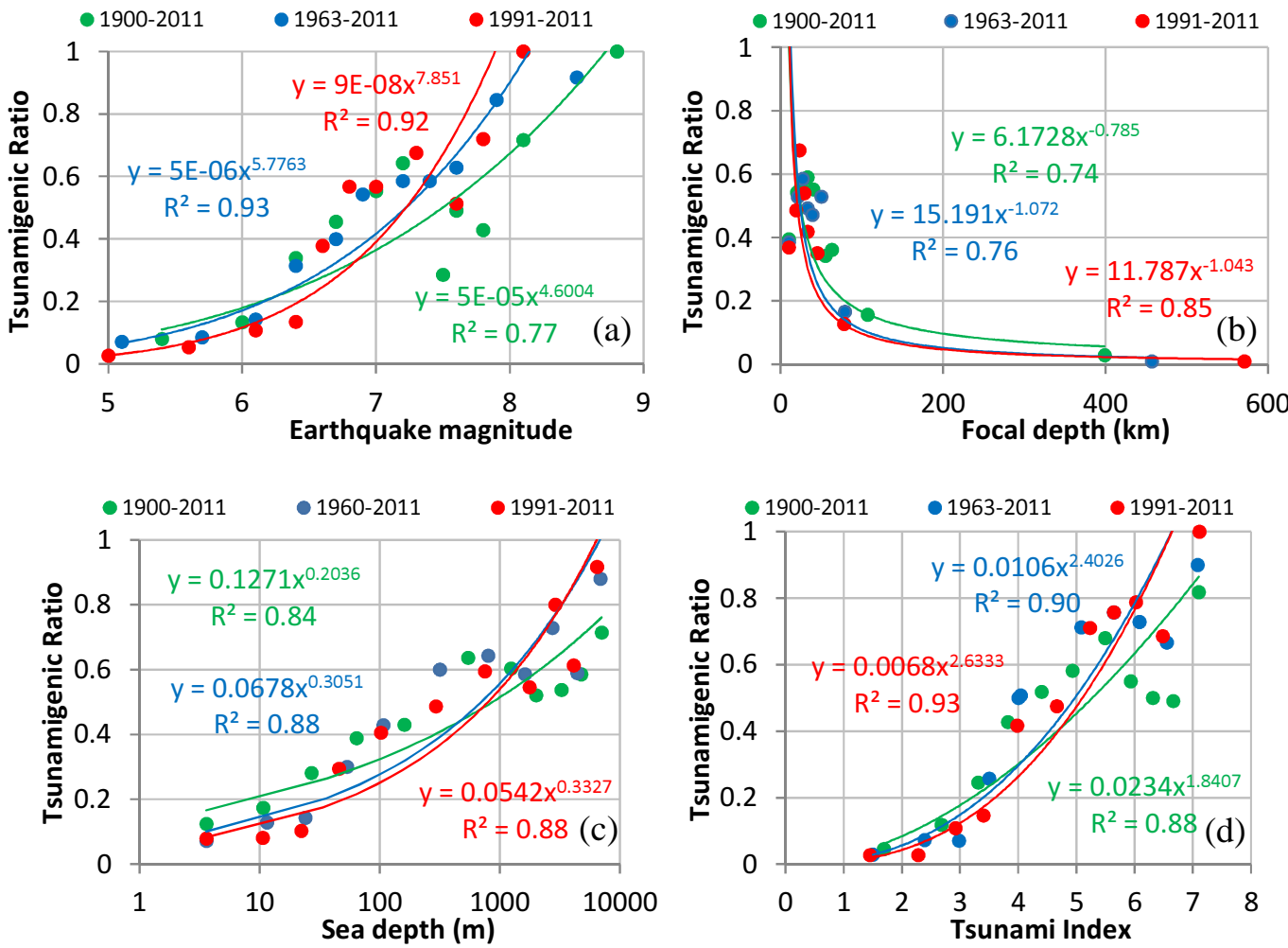

Fig. 3. Tsunamigenic ratios of the entire Pacific region for three different periods with regression analysis using power function.
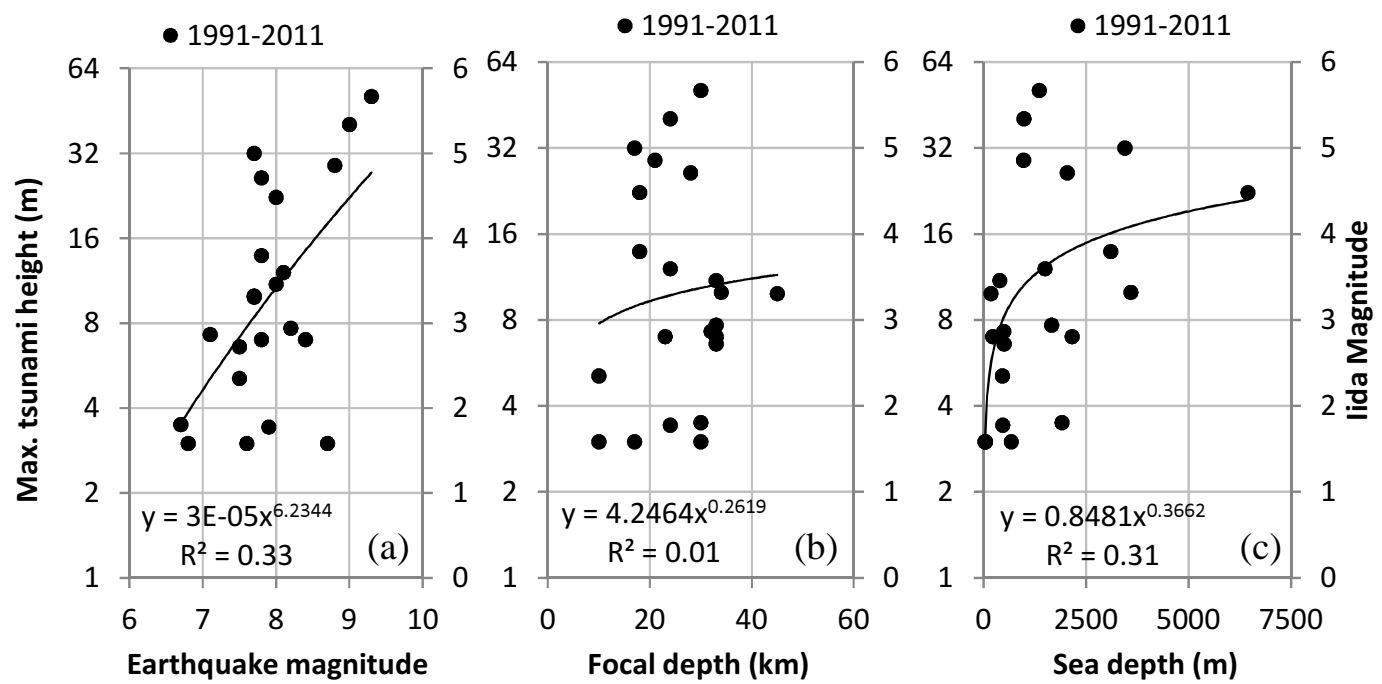

Fig. 4. Relationship between the earthquake magnitude/focal depth/sea depth and the maximum tsunami height and Iida magnitude of recent tsunamis causing death events.

\section{Proposal for a Tsunami Index}

According to the previous Fig. 2a-c, greater earthquake magnitude has a high possibility of tsunami occurrence (generally $M>7.0$ ), shallower focal depth has high possibility of tsunami occurrence (generally focal depth $<100 \mathrm{~km}$ ), and deeper sea depth has high possibility of tsunami occurrence (generally sea depth $>1000 \mathrm{~m}$ ). Combining the above three parameters would help provide a better understanding of tsunami generation mechanism. Consequently, a new parameter that includes the effect of the three parameters is 


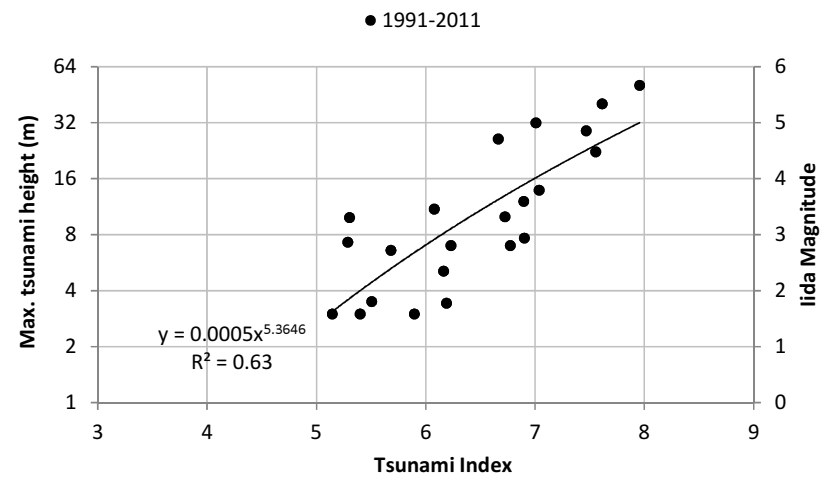

Fig. 5. Relationship between the tsunami index and the maximum tsunami height and lida magnitude of recent tsunamis causing death events.

proposed in a dimensionless form, called the Tsunami Index (TI), as expressed in Eq. (1).

$\mathrm{TI}=$ Magnitude $+\log \left(\frac{\text { Depth }_{\text {sea }}}{\text { Depth }_{\text {focal }}}\right)$

From the equation, the range of the tsunami index varies from 0 to about 10.0 (extremely lowest to highest theoretical case). For example, TI $=0$ when magnitude $=5.0$, focal depth $=100 \mathrm{~km}$ and sea depth $=10^{-3} \mathrm{~km}$, and TI $=10.0$ when magnitude $=9.0$, focal depth $=1 \mathrm{~km}$ and sea depth $=10 \mathrm{~km}$.

The results with smaller variation are plotted in Fig. $2 d$ and Fig. 3d. In general, $R^{2}$ for TI is higher than $R^{2}$ for earthquake magnitude, focal depth and sea depth itself. In other words, a combination of the three mentioned parameters as proposed with introduction of TI helps reinforce the relationship between these parameters and the tsunami generation. In case of TI, $R^{2}$ increases from 0.88 (data during 1900-2011) to 0.90 (data during 1960-2011) and to 0.93 (data during 1991-2011). The TR starts from the tsunami index (TI) equal to 2.0 , increases to 0.50 when $\mathrm{TI}$ is at 5.0 and reaches 0.80 when TI becomes 7.0. In general, when period 1900-2011 is considered, the coefficient of determination, $R^{2}$ increases from 0.77 (earthquake magnitude), 0.74 (focal depth) and 0.84 (sea depth) to 0.88 when the TR are plotted against the proposed TI. In addition, $R^{2}$ for the case when only the modern instrumental period (red line) is considered is as high as 0.93 . It can be noticed from the results that the blue and red lines are similar in most parameters and get along with the TR results, as explained in the previous section and in Table $4 \mathrm{~b}$. For the whole Pacific region, TR is more than 0.5 when TI is larger than 5 and TR reach 1.0 when TI is almost 8. The blue and red lines in Fig. 3 are steeper than the black line, implying that the recent tsunamis caused greater tsunami generation potential than they did in the past hundred years. Although the TR during 1991-2011 (0.40) is slightly less than the TR prior $1900(0.46)$ (Table 4a), the TR during 1991-2011 gradually becomes higher when the TI is greater than 5. In other words, a tsunami is almost definitely generated if a computed $\mathrm{TI}$ is greater than 7.0 (for example, magnitude $>8.0$, focal depth $<10 \mathrm{~km}$ and sea depth $>1000 \mathrm{~m}$ ). This means that the TR of the recent events is higher than the historical events when a powerful tsunami is expected to be generated.

This section also discusses and compares "hazards" (the maximum tsunami height and the TR). Recent tsunamis causing death events during 1991-2011 are summarized in Table 5. Most of them were generated with an earthquake magnitude greater than 7.5, which is 19 from the total of 22 events. The range of TI value from 5.14 to 7.96 was calculated based on the previously mentioned data and plotted against the maximum tsunami height (up to $50 \mathrm{~m}$ ). Figure 4 shows a plot of 22 events during 1991-2011 with information on earthquake magnitude, focal depth, sea depth, tsunami height and Iida tsunami magnitude $\left(M_{\mathrm{I}}\right)$ (Iida et al., 1967). The relationship between the maximum tsunami height and the TI for tsunamis during 1991-2011 is shown in Fig. 5. Although a relationship between TI and TR using these three parameters is unclear, $R^{2}$ obtained from the plot using data from 1991-2011 against the proposed TI is increased from 0.33 to 0.63 (Fig. 5). However, there are some important points that might cause uncertainty in this calculation, such as the lack of instrumental records in the past. For instance, the total number of earthquakes prior to 1900 is only 466, whereas there were already 381 events during 1991-2011 from the total of 1217 during 1900-2011 (Table 4b). Modern technology, such as earthquake measurement technology and high-resolution satellite images, help to increase the accuracy of earthquake and tsunami information. For example, better earthquake magnitude and focal depth can now be obtained. For the tsunami height, a better transportation system also supports accessibility to highly affected areas. Although an effect from global warming is still unclear, the measured maximum tsunami height of the recent tsunamis (1991-2011) might be closer to the actual maximum tsunami heights.

\section{Application of Tsunamigenic Ratio and Tsunami Index}

Application of TR and TI can be explained as follows. A tsunami is very likely to be generated if a calculated TI is greater than 7.0. Moreover, 6 levels can be classified for an early tsunami warning: tsunami advisory $(\mathrm{TI}<3$ and $\mathrm{TR}<0.1$ ), small tsunami ( $\mathrm{TI}<4$ and $\mathrm{TR}<0.3$ ), moderate tsunami (TI $<5$ and TR $<0.5$ ), major tsunami (TI $<6$ and $\mathrm{TR}<0.7)$, destructive tsunami $(\mathrm{TI}<7$ and $\mathrm{TR}<0.9)$ and devastating tsunami $(\mathrm{TI} \approx 8$ and $\mathrm{TR} \approx 1.0)$, as shown in $\mathrm{Ta}$ ble 6. One good example of using TI is that TI can express the increasing trend of maximum tsunami height over the recent tsunamis causing death, while earthquake magnitude, focal depth, and sea depth itself cannot because low values 
Table 5. Recent tsunamis causing death from 1991 to 2011 and related information.

\begin{tabular}{|c|c|c|c|c|c|c|}
\hline Year & Location & Deaths & $\begin{array}{c}\text { Earthquake } \\
\text { magnitude }\end{array}$ & $\begin{array}{r}\text { Tsunami } \\
\text { Index }\end{array}$ & $\begin{array}{r}\text { Maximum } \\
\text { tsunami } \\
\text { height }(\mathrm{m})\end{array}$ & $\begin{array}{r}\text { Tsunami } \\
\text { Magnitude }\end{array}$ \\
\hline 1991 & Costa Rica & 2 & 7.6 & 5.14 & 3.0 & 1.58 \\
\hline 1992 & Nicaragua & 170 & 7.7 & 5.30 & 9.9 & 3.31 \\
\hline 1992 & Flores Sea, Indonesia & 1169 & 7.8 & 6.66 & 26.2 & 4.71 \\
\hline 1993 & Okushiri, Japan & 208 & 7.7 & 7.01 & 32.0 & 5.00 \\
\hline 1994 & Java, Indonesia & 250 & 7.8 & 7.04 & 13.9 & 3.80 \\
\hline 1994 & Halmahera, Indonesia & 1 & 6.8 & 5.40 & 3.0 & 1.58 \\
\hline 1994 & Mindoro, Philippines & 81 & 7.1 & 5.29 & 7.3 & 2.87 \\
\hline 1995 & Mexico & 1 & 8.0 & 6.08 & 11.0 & 3.46 \\
\hline 1996 & Sulawesi, Indonesia & 9 & 7.9 & 6.19 & 3.4 & 1.78 \\
\hline 1996 & North Peru & 12 & 7.5 & 6.16 & 5.1 & 2.35 \\
\hline 1996 & Irian Jaya, Indonesia & 110 & 8.2 & 6.90 & 7.7 & 2.94 \\
\hline 1999 & Vanuatu & 5 & 7.5 & 5.68 & 6.6 & 2.72 \\
\hline 2001 & Southern Peru & 26 & 8.4 & 6.23 & 7.0 & 2.81 \\
\hline 2004 & Sumatra, Indonesia & 227898 & 9.3 & 7.96 & 50.9 & 5.67 \\
\hline 2005 & Sumatra, Indonesia & 10 & 8.7 & 5.89 & 3.0 & 1.58 \\
\hline 2006 & Seram, Indonesia & 4 & 6.7 & 5.50 & 3.5 & 1.81 \\
\hline 2006 & Java, Indonesia & 802 & 7.7 & 6.76 & 10.0 & 3.32 \\
\hline 2007 & Solomon Islands & 52 & 8.1 & 7.05 & 12.1 & 3.60 \\
\hline 2009 & Samoa Islands & 192 & 8 & 7.54 & 22.4 & 4.48 \\
\hline 2010 & Southern Chile & 156 & 8.8 & 7.43 & 29.0 & 2.81 \\
\hline 2010 & Sumatra, Indonesia & 431 & 7.7 & 6.97 & 7.0 & 4.86 \\
\hline 2011 & East Japan & 19294 & 9.0 & 7.61 & 40.5 & 5.34 \\
\hline
\end{tabular}

Table 6. Decision support for early tsunami warning using tsunami index and the proposed tsunami intensity and tsunami magnitude.

\begin{tabular}{|c|c|c|c|c|c|c|}
\hline \multicolumn{3}{|c|}{$\begin{array}{l}\text { Tsunami } \\
\text { Index }\end{array}$} & \multicolumn{2}{|r|}{$\begin{array}{l}\text { Tsunami } \\
\text { Intensity }\end{array}$} & \multirow{2}{*}{$\begin{array}{r}\text { Tsunami } \\
\text { height } \\
(\mathrm{m})\end{array}$} & \multirow{2}{*}{$\begin{array}{r}\text { Tsunami } \\
\text { magnitude } \\
M_{\mathrm{I}}\end{array}$} \\
\hline $\begin{array}{r}\text { Index } \\
\mathrm{TI}\end{array}$ & $\begin{array}{r}\text { Generation ratio } \\
\text { TR }\end{array}$ & $\begin{array}{l}\text { Tsunami } \\
\text { description }\end{array}$ & $\begin{array}{c}\text { Intensity } \\
I\end{array}$ & $\begin{array}{l}\text { Intensity } \\
\text { definition }\end{array}$ & & \\
\hline 3 & 0.1 & Advisory & $\mathrm{I}-\mathrm{V}$ & Not felt - Strong & 1 & 0 \\
\hline 4 & 0.3 & Small & VI & Slightly damaging & 2 & 1 \\
\hline 5 & 0.5 & Moderate & VII-VIII & Damaging - Heavily damaging & 4 & 2 \\
\hline 6 & 0.7 & Major & IX-X & Destructive - Very destructive & 8 & 3 \\
\hline 7 & 0.9 & Destructive & XI & Devastating & 16 & 4 \\
\hline 8 & 1.0 & Devastating & XII & Completely devastating & 32 & 5 \\
\hline
\end{tabular}

of $R^{2}$ are obtained (Fig. $4 \mathrm{a}-\mathrm{c}$ ). This result is verified and has a somewhat good agreement with the tsunami magnitude (Iida et al., 1967) in Fig. 5 and can be expressed together with the tsunami intensity and corresponding tsunami height (Papadopoulos and Imamura, 2001) in Table 6 when the logarithmic scale (base 2) is used for the tsunami height.

\section{Conclusions}

The Pacific Ocean is the location where two-thirds of the tsunamis have occurred. Countries surrounding the Pacific Ocean suffered from many tsunamis that caused a great number of deaths. This study utilized the historical tsunami database in the Pacific to compute the TR, which is defined as the ratio between the number of earthquake-generated tsunamis and the total number of earthquakes. The average TR in the Pacific Ocean is about 0.40, whereas the TR for 
each region varies depending on the selected data period, preinstrumental (prior 1900), early instrumental (1900-1962), instrumental (1963-1990) and modern instrumental (1991 to 2011). The TR for each region was calculated and shows the relationship between three influential parameters: earthquake magnitude, focal depth and sea depth. The results show that a greater magnitude earthquake at shallower focal depths has a high potential to generate tsunamis with a large tsunami height. The tsunami index (TI) was proposed to express the influence on tsunami generation and maximum tsunami height of the three parameters summarized above in one parameter and to successfully increase the coefficient of determination, $R^{2}$. This study indicates that recent submarine earthquakes had a higher potential to generate a tsunami with larger tsunami heights than during the entire the last century. TR and TI are verified and can be well expressed together with the early proposed tsunami magnitude and tsunami intensity. The proposed TR and TI might be an important parameter for a decision support tool during the early tsunami warning stage or for future tsunami risk assessments.

Acknowledgements. We express our deep appreciation to the Willis Research Network (WRN), the Ministry of Education, Culture, Sports, Science and Technology (MEXT) and the Industrial Technology Research Grant Program in 2008 (Project ID: 08E52010a) from the New Energy and Industrial Technology Development Organization (NEDO) for the financial support of this study. We also would like to express our profound gratitude for very useful comments and suggestions from editor and reviewers.

Edited by: S. Tinti

Reviewed by: V. K. Gusiakov and another anonymous referee

\section{References}

Abe, K.: Size of great earthquakes of 1837-1974 inferred from tsunami data, J. Geophys. Res., 84, 1561-1568, 1979.

Asian Disaster Preparedness Center (ADPC): Project ReportActivity 1.2 Model Evaluation: End-to-end early warning of tsunamis and other natural hazards for disaster preparedness and mitigation in the Indian Ocean and Southeast Asia: Phase 2, UNESCAP, 2009.

Global Centroid Moment Tensor, (Global CMT): Global CMT catalog search, Harvard University, Cambridge, MA, USA, available at: www.globalcmt.org/CMTsearch.html (last access: 14 July 2011), 2011.

Gusiakov, V. K.: Tsunami generation potential of different tsunamigenic regions in the Pacific, Mar. Geol., 215, 3-9, doi:10.1016/j.margeo.2004.05.033, 2005.

Hatori, T.: Magnitude scale for the Central American tsunamis, Pure Appl. Geophys., 144, 471-479, doi:10.1007/BF00874379, 1995.

Iida, K., Cox, D. C., and Pararas-Carayannis, G.: Preliminary cata$\log$ of tsunamis occurring in the Pacific Ocean, Hawaii Inst. Geophy., Hawaii Univ. Data Report 5, HIG 67-10, 131 pp., 1967.
Imamura, F. and Abe, I.: History and challenge of tsunami warning systems in Japan, J. Disaster Res., 4, 267-271, 2009.

Kanamori, H.: Mechanism of tsunami earthquakes, Phys. Earth Planet., 6, 346-359, doi:10.1016/0031-9201(72)90058-1, 1972.

Lockridge, P. A. and Smith, R. H.: Tsunamis in the Pacific Basin, 1900-1983 (map), Boulder, CO, NOAA/NGDC, 1984.

Mansinha, L. and Smylie, D. E.: The displacement fields of inclined faults, Bull. Seism. Soc. Am., 61, 1433-1440, 1971.

National Oceanic and Atmospheric Administration (NOAA): National Geophysical Data Center (NGDC) GEODAS Grid Translator - Design-a-Grid (ETOPO2), NGDC, Washington DC, available at: www.ngdc.noaa.gov/mgg/gdas/gd_designagrid.html (last access: 7 October 2011), USA, 2011a.

National Oceanic and Atmospheric Administration (NOAA): National Geophysical Data Center (NGDC), Earthquake Data and Information at NGDC, NGDC, Washington DC, USA, available at: http://www.ngdc.noaa.gov/hazard/earthqk.shtml (last access: 7 October 2011), 2011b.

National Oceanic and Atmospheric Administration (NOAA): National Geophysical Data Center (NGDC), NOAA/WDC Historical Tsunami Database at NGDC, , NGDC, Washington DC, USA, available at: www.ngdc.noaa.gov/hazard/tsu_db.shtml (last access: 7 October 2011), 2011c.

Okada, M. and Tanioka, Y.: Earthquake magnitude, depth and generation rate of tsunami, Kaiyo monthly, 15, 18-22, 1998 (in Japanese).

Okada, Y.: Surface deformation due to shear and tensile faults in a half space, Bull. Seism. Soc. Am., 75, 1135-1154, 1985.

Papadopoulos, G. A. and Imamura, F.: A proposal for a new tsunami intensity scale, in: Proc. International Tsunami Symposium, Seattle, Washington, 5, 569-577, 2001.

Papazachos, B. C., Scordilis, E. M., Panagiotopoulos, D. G., Papazachos, C. B., and Karakaisis, G. F.: Global relations between seismic fault parameters and moment magnitude of earthquakes, Bull. Geol. Soc. Greece 36, Proc. of the 10th International Congress, Thessaloniki, Greek, 2004.

Ruangrassamee, A.: Tsunami Generation Mechanism, SCRATCH Workshop, Asian Institute of Technology, 21 November 2006.

Satake, K. and Tanioka, Y.: Sources of tsunami and tsunamigenic earthquakes in subduction zones, Pure Appl. Geophys., 154, 467-483, doi:10.1007/s000240050240, 1999.

Scordilis, E. M.: Empirical global relations converting $M_{S}$ and $m_{b}$ to moment magnitude, J. Seismol., 10, 225-236, doi:10.1007/s10950-006-9012-4, 2006.

Suppasri, A., Asada, T., Imamura, F., and Koshimura, S.: Tsunami Hazard and Risk Assessment for Coastal Population in the Indian Ocean, in: Proceedings of the International Union of Geodesy and Geophysics (IUGG2011), Melbourne, Australia, Advances in Tsunami Science, Warning, and Mitigation (IASPEI-JS01S5), 2 July 2011, 2011a

Suppasri, A., Imamura, F., and Koshimura, S.: Tsunamigenic Rate of the Pacific Ocean Earthquakes, in: Proceedings of the Japan Geoscience Union meeting (JpGU2011), Chiba, Japan, Multidisciplinary Studies on Natural Hazard in Asia (H-DS04), 27 May 2011, 2011b.

Suppasri, A., Koshimura, S., and Imamura, F.: Developing tsunami fragility curves based on the satellite remote sensing and the numerical modeling of the 2004 Indian Ocean tsunami in Thailand, Nat. Hazards Earth Syst. Sci., 11, 173-189, doi:10.5194/nhess- 
11-173-2011, 2011c.

Suppasri, A., Imamura F., and Koshimura S.: Probabilistic tsunami hazard analysis and risk to coastal population in Thailand, J. Earthq. Tsunami., 6, in press, 2012a.

Suppasri, A., Imamura, F., and Koshimura, S.: Tsunami hazard and casualty estimation in a coastal area that neighbors the Indian Ocean and South China Sea, J. Earthq. Tsunami, 6, in press, 2012b.

Suppasri, A., Koshimura, S., Imai, K., Mas, E., Gokon, H., Muhari, A., and Imamura, F.: Damage characteristic and field survey of the 2011 Great East Japan tsunami in the Miyagi prefecture, Coast. Eng. J., 54, Special Issue of the 2011 Tohoku Tsunami, in press, 2012c.
Tinti, S.: Assessment of tsunami hazard in the Italian Seas, Nat. Hazards. 4, 267-283, doi:10.1007/BF00162792, 1991.

Wells, D. L. and Coppersmith, K. L.: New empirical relationships among magnitude, rupture width, rupture area, and surface displacement, Bull. Seism. Soc. Am., 84, 974-1002, 1994.

US Geological Survey (USGS): National Earthquake Informaion Center (NEIC), US Geological Survey, Washington DC, USA, available at: http://earthquake.usgs.gov/ (last access: 7 October 2011), 2011. 